\title{
Knowledge management strategies for leadership in the digital business environment
}

\author{
Camelia BĂEŞU \\ "Stefan cel Mare" University of Suceava, Suceava, Romania \\ cameliab@seap.usv.ro \\ Ruxandra BEJINARU \\ "Stefan cel Mare" University of Suceava, Suceava, Romania \\ ruxandrab@usm.ro
}

\begin{abstract}
Throughout this paper we try to propose several updated theories about leadership strategies considering the new framework and coordinates imposed by the digital age. By operating a literature review, firstly we will define the intriguing concepts of: digital age, digital leader and digital leadership. Nowadays leaders must understand the global technological revolution and integrate with it in their daily business routine. Within the sections of the paper we will analyze the different features of the digital knowledge age, considering issues like the work environment, the new type of employees or the new skills. We believe that by mapping all these novel aspects we will emphasize which are the gaps between the current state and the potential one. Acknowledging the opportunities of the digital age is empowering both for managers and employees in terms of achieving their success. We will provide an analysis of the most important traits of a digital leader and their necessity in the present environment. Even if great theorists consider that a leader's essential characteristics are timeless we will argue which are the substantial changes generated by digitalization. Furthermore, we will discuss the potential knowledge strategies to be applied for effective leadership in the digital business environment. Throughout this paper we want to bring to attention which are the major impactful connections between the trends of digitalization and leadership concepts. In the final section of the paper we will present our conclusions and propose for discussion further challenges of the digital age, mainly from managerial perspective.
\end{abstract}

Keywords: digitalization, digital age, digital leader, digital leadership, knowledge strategies, employee skills.

\section{Transformations generated by digitalization in the business environment}

The already well-known 'digitalization' phenomenon has led to digital transformation of doing business, of working and of leading the workers. Most commonly, expressions such as 'digitalization' and 'digital transformation' are perceived as synonymous and referring mainly to the dramatic changes caused by the rapid and massive advance of technology (Chew, 2013).

The emerging of industry 4.0 is stimulating the knowledge revolution and its leading it to another level in all domains, including higher education (Bejinaru \& Prelipcean, 2017). Industry 4.0 proposes a new business and organization management infrastructure through a diversified offer of high-tech tools, such as: social media, forums, blogs or virtual networks. The latter being the most recognized infrastructure, however the knowledge portals have an essential place in the strategic management of the organizational knowledge improving the operations of knowledge management developed at the company's level (Bejinaru \& Iordache, 2010). Through these portals the managers together with the employees access, create, organize, share and use the knowledge in their work. The major advantage obtained by using this type of tool is to provide free and transparent access to all the knowledge included in the organization and thus facilitates the expansion of businesses through direct access to employees and customers, saving time, 
money, space and other resources (Avital et al., 2017; Mahdi et al., 2018). The potential benefit of technology for any business company is to stimulate collaborative work and thus produce a dramatic change in culture and custom of knowledge management (Bratianu \& Pinzaru, 2015; Bratianu \& Bejinaru, 2019). In this sense, we refer to the change optimization, based on the digitization, communication, collaboration, information exchange, learning and especially decision making (Dima \& Ghinea, 2016; Dima et al., 2017). Massive digitalization has also disadvantages and implies knowledge risks, like fake news, fabricated data, unverified data, fuzzy knowledge and other (Allcott \& Gentzkow, 2017).

Considering the availability of all these tools of digitalization, the organization has the opportunity to create knowledge networks in which employees with different specializations, with different backgrounds and different work experience, collaborate dynamically and openly to create new knowledge, to develop new processes and especially to share their knowledge in the most useful way possible, at this moment. It is important that not only these internal agents can contribute to the performance of the organization, but also a significant role in the process of organizational innovation and change, have as well external agents, such as universities, consulting firms, associations and other organizations. For organizational development, it is necessary that access to knowledge is free and vast (Costa \& Monteiro, 2016).

The concept of 'digital age' is acknowledged as encompassing several combinations of terms, like: digital organization, digital transformation, digital leader, digital skills, digital resources and derivative expressions, like: digitalization, digitization, digitally, digitized. Even if there is a general mega-trend of discussing all issues in relation to the 'digital age' there are certain clarifications necessary to be made, like the distinction between the terms of "digitalization" and "digitization" because even if they appear to have the same meaning, they refer to different aspects. "Digitization" is a term used to describe the process of retrieving analog information and encoding it so that computers can recognize, process, store and then transmit it to users (Bloomberg, 2018). The digitization process is important in the business sector in order to obtain analogical type of information and for streamlining "paper-based" processes - where "paper-based" is nothing more than a metaphor. In fact, digitization means that ,the information" is what we digitize, not „the processes" - this is where "digitalization" begins. The term of "digitalization" is simply defined as "changes associated with the application of digital technology in all aspects of human society". Digitalization is also accepted as "the ability to transform existing products or services into digital variants, thus offering advantages over the tangible product" (Parviainen et al., 2017, p.64). The process of digitalization influences some other organizational processes, especially organizational change and transformational leadership. As argued before, it is important to make the distinction and acknowledge clearly their meaning in order to use them when needed "because their usefulness and effects differ" and thus we should decide which process to implement, either "digitization" or "digitalization" (Bejinaru, 2019, p.368).

Business digitalization implies many technical and technological issues, connected to the operational level of companies' activities but it is also influencing the managerial level in terms of business strategy, of employees motivation, of marketing policies or of collaborative tools. The technological advancements have simultaneously emerged and impacted the business sector. Actually, recent data from the CEC Report "Management in the Digital Era" (2018) reflects real evidence that implementation of different digital technologies has a strongly positive effect on 
businesses cash flows in various sectors, rather than, the zero level, of the so-called consideration of introducing digital technology in the business, as shown in the figure no. 1 below:

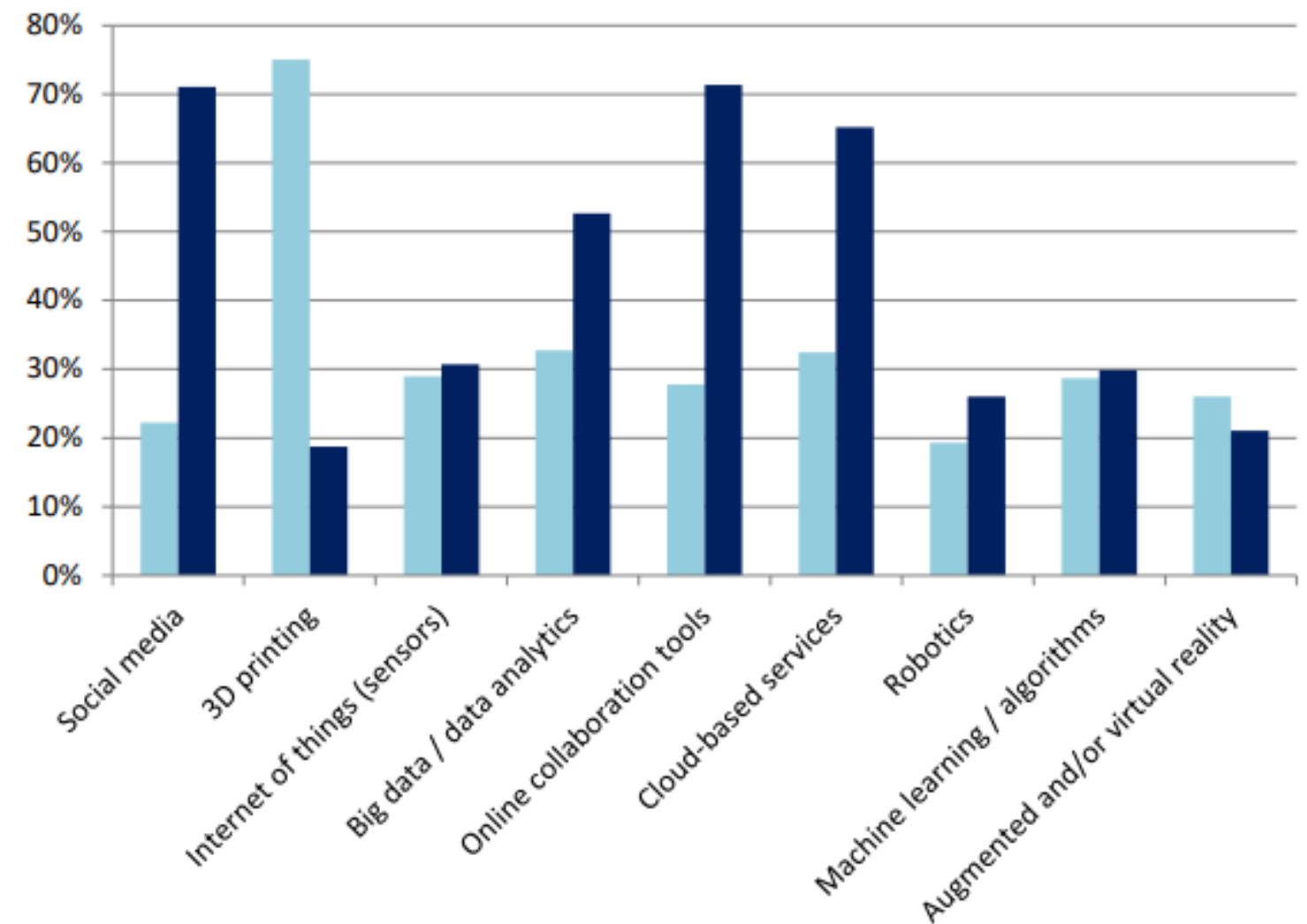

PICBE | 648

- : considering

- implemented

Figure 1. Consideration vs. Implementation of digital technologies

Sources: adaptation after (CEC, 2018)

There are two most interesting aspects reflected by the data in figure 1 . We consider that the first one is the strong positive effect generated by the implementation of 'Social media' in the business, which, at this point of its propagation it's obvious to be easily comprehended. The second one is reflecting the even greater influence of ' $3 D$ printing', perceived only at its potential stage, registered only at the considering stage. According to the data presented in figure 1, we can assure that digital technologies, like: Social media, 3D printing, IoT (Internet of Things), Big data analytics, Online collaboration tools, Cloud-based service, Robotics, Machine learning and Virtual reality, are bringing real benefits for businesses all around the world.

What we have proposed through this paper is to highlight the closest connections between the phenomena of technological development, the propagation of digital technologies, the implementation of digitalization and the managerial approaches possible at the company level. We believe that, at this moment, the connection between technology, management and 
organizational practices must evolve together, in an integrated way, in order to increase productivity and improve performance at the level of business companies (Hapenciuc et al., 2016; Neamtu et al., 2019). Further we will approach novel aspects about current leadership theories.

\section{Challenges of current digital leadership theories}

First, let's state a rhetorical question, whether leaders are or not ready for leading in a digital business environment? In the literature, we have identified three aspects that make it difficult for managers to face the digital business environment. First of all, a major barrier is the lack of digital education of managers coupled with an outdated management mentality. It is interesting to analyze, the perspectives that emerged from a study published by MitSloan Management Review (Ready et al., 2020) regarding the professional and mental training of managers for the specific of business in the digital age. Thus, this research hypothesis received 3 different and contradictory answers, that are: (1) only 9\% expressed their complete agreement regarding the fact that they already have managers ready to run the business implementing digital processes and techniques; (2) $12 \%$ all agreed that the leaders of the organization have the right mentality to embrace the changes needed to thrive in the digital economy; and (3) 13\% checked the total agreement considering that the organization is ready to compete in the digital economy. These numbers show that the respondent leaders acknowledge the importance of digital savvy-ness and thus consider themselves unsecure and unprepared for facing the digital workplace.

A second perspective that demonstrates the lack of preparedness of leaders is the blind spots, which can be strategic, cultural, human capital or personal. For example, the strategic blind spots, refer to the fact the leader is not prepared to understand the revolutionary changes according to which they must develop their businesses. Blind spots for cultural issues describe the rigid organizational culture, where changing or adaptation of norms and habits is considered an affront. The human capital blind spots reveal that a company's methods of recruiting, motivating or working with employees are outdated and irrelevant for the momentum workforce. The personal blind spots are generated in the cases where the managers surround themselves by people like them and don't leave access to fresh perspectives from different persons, with different education and background.

The third obstacle that managers are not prepared to overcome is the embedded tension that affects the relationship with employees. The demands of high performance and high speed of operations in the digital economy cause difficult issues and tensions in the collaboration with employees as they negotiate increasingly aggressive benefits against the work performed (Ready et al., 2020). Even if technology and devices have improved operations and performance, there is still a great demand for skilled human workforce able to manage the digitalized jobs. Acknowledging their work rating, employees have gained confidence to ask for higher wages and more benefits in the work place (Culpin et al., 2015; Do et al., 2018).

In order to identify more guidance into the debate of digital leadership, we recurred to the characteristics of this concept provided by Weinman (2015) which are: technology leadership, digital visioning and digital execution. Furthermore, we found that digital leadership consists of five more characteristics, presented by Zhu (2015) as the following: (1) Thought leader, meaning tough capability of facing the fierce competition on the market. (2) Creative leader, as digital technology generates continuously new business models and provides borderless impact to the innovation, the leader must prove the capability of implementing future business ideas. (3) Global Visionary Leader, a digital leader has the ability to become a driver of change and provide 
direction towards the digital business transformation. (4) Inquisitive Leader, implies the urgently scanning and analyzing the VUCA environment dimensions (Volatility, Uncertainty, Complexity \& Ambiguity) (5) Profound Leader, suggests the in depth understanding of internet policy, of digital networking, of information access and all related issues to the digital environment (Zhu, 2015).

To state a bottom line for the above numerous capabilities of the digital leader and

PICBE | 650 leadership, we summarize that digital leadership is defined mainly by the capability of combining authentic leadership skills (meaning visionary skills and transformational skills) with the digital skills, consisting of digital knowledge and digital experience. In this context, a digital leader is characterized by creativity, vision, profound thinking and inquiry.

\section{Capabilities of the 'digital leader'}

The definition of the digital leader encompasses a large palette of features, combining the classic leadership theories and the new digitalization specific requirements. We appreciate that is more adequate to speak about the leader's role in the digital age, the leader's capabilities in the digital age, or the leader's strategies in the digital age (Baesu, 2018; Hill, 2013). But literature and massmedia have 'innovated' this subject and proposed various expressions and descriptions. We shall further discuss a few in order to differentiate and extract the essence of each perspective, symbolically represented in figure 2 .

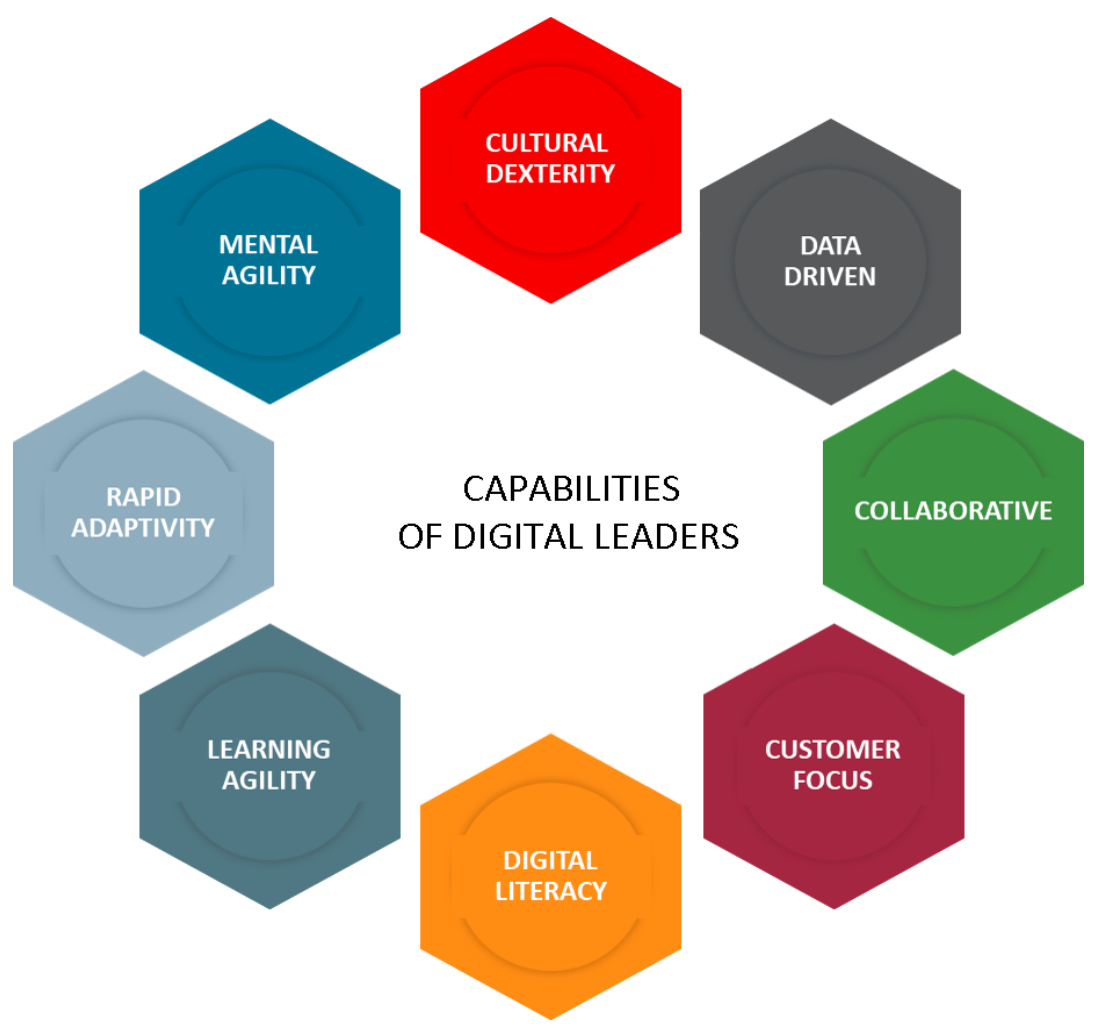

Figure 2. Capabilities of digital leaders

Source: adapted after (https://blogs.oracle.com/sandye/evolving-leadership-for-the-digital-age) 
The capabilities associated to the digital leader are framework dependent and dynamic, which implies that we shall present a series of reference capabilities. Leaders' skills, capabilities or competences have always been a topical issue and continue to be discussed due to the changing coordinates of the business environment (illustrated in figure 2). First of all, when we speak about the digital business context we must speak also about "digital literacy". In this sense, it is fundamental not only to acknowledge the new technological resources and tools but also to use them, to implement them in order to improve the business performance and thus to ensure a better level of "digital literacy" at organizational level. Digital literacy is a must-have capability for leaders as they are icons for their employees and partners and by providing their own example they actually promote the learning and comprehension of technological innovations (Hadad \& Bratianu, 2019).

Learning agility is a capability that involves a certain work and life experience on the basis of which leaders can draw conclusions and lessons learned. Learning agility is a different ability than traditional learning, i.e. it involves learning adapted to experiences, context, resources and goals. The most important aspect of learning agility is that it leads to progress and process optimization. Similarly, mental agility represents a 'state-of-the-art' capability and requires the highest quality components, such as: the ability to think critically and to understand the connections between the problems to be solved. Leaders have always been confronted with strategic decisions, but now, in the digital age, leaders are required to be the more agile, critical, precise but especially fast thinking. Those leaders who can rely on mental agility are really effective in a global competitive environment (Maravilhas \& Martins, 2018; Vatamanescu et al, 2017).

The digitization age offers an easier prospecting of the market and a more accurate 'reading' of the clients' needs, which also presents advantages and disadvantages. The volume of information about clients, their variety and their high degree of specificity, can pose difficulties for companies in order to satisfy the needs of their clients (Griffith \& Hoppner, 2013). The focus on the clients must be felt by them through the quality but also the speed of the services offered. Leaders, along with their teams, must constantly monitor clients and have the capability of being 'customer focused' on meeting their needs.

The capability to be 'data driven' is a fundamental one as only a leader can have the ability to use data to improve decision making and business performance. Being focused on data, in the digital age, has a different meaning. Since the data is always available to the leader, the leader must know how to use them effectively, depending on the objective pursued.

A new capability, requested and generated simultaneously, of the digital age, is 'cultural dexterity'. Since the digital environment is one virtual through its nature, it can become very easy multicultural too. Moreover, the option of remote work is one that is increasingly accessed by employees, so that the management of the employee teams is done intercultural and in locations all over the world. In such a work environment, and with employees from different cultures, it is imperative that leaders develop their capacity for 'cultural dexterity'. Also in connection with the problem of employee management and the specific way of working in digital age, the need for collaborative work has arisen. Thus, the leader must develop his ability to act inclusive, involving with confidence, transparency and honesty the employees in the current and strategic decision problems of the organization.

Not least, the importance of the ability to adapt quickly to changes must be claimed. Sure it's not a new capability, but it has a certain specificity generated by digitization. In the digital 
age, 'fast adaptivity' implies both a much faster rate of change and agility to choose from the multitude of possible options / solutions - the best one. Leaders are defined by proactivity, innovation, inspiration and in addition, they will also need this capability called 'rapid adaptivity' (Elvington, 2017).

\section{Knowledge management strategies in the Digital Age}

PICBE | 652

When speaking about the re-use of knowledge, we should clearly envision the benefits it generates from, at least, three different perspectives: benefits for the employees, benefits for the processes and benefits for the organization. For sure that these issues are already known and implemented but it is essential to make a clear distinction and acknowledge each perspective in terms of cause and effects. The adequate strategies of re-using knowledge can generate a series of advantages for employees like facilitation of developing new knowledge based on previous knowledge resources; an important benefit is faster access to knowledge, which reduces the time of searching, collecting and extracting the necessary knowledge from external sources; a positive effect of knowledge re-use for employees is the ease of sharing improvements of their work; at the end, all these advantages support a knowledgeable worker who is truly valuable for the organization (Ahmad et al., 2017; Bejinaru \& Hapenciuc, 2016; Hadad, 2017).

At the level of processes, knowledge re-use will contribute to generate new ideas and thus to achieving novel approaches of processes; the re-use of knowledge will conduct to faster problem-solving, by eliminating the barriers encountered when asking for information, when testing some solutions or when analyzing feedback; actually, at this point we can strongly reaffirm that knowledge has an exponential effect, and the more it is used, the more benefits it generates, thus use-and-re-use of knowledge shall only increase positive results and lead to continuous improvement (Bejinaru, 2017). The above-mentioned benefits and advantages of knowledge re-use can be reformulated to reflect the organizational level. In this sense, we argue that knowledge re-use shall definitely generate innovation for the entire organization. The faster access to knowledge and the faster rhythm of solving problems will contribute to better efficiency and thus the organization will register better performance. That implies a very well understanding of knowledge dynamics (Bratianu \& Bejinaru, 2020), and a shift in business education (Bratianu, Hadad \& Bejinaru).

We remind the fact that a well-established knowledge management will reduce the loss of knowledge at organizational level which is a positive effect, though it is rarely noticed and discussed. Issues like intellectual capital, knowledge creation, knowledge sharing, knowledge retention, knowledge loss and knowledge risks are critical for the organizational performance but they have been too scarcely approached (Bratianu, 2018a, b). As a bottom line, knowledge re-use is supporting a knowledgeable worker, is supporting continuous improvement of processes and is driving better productivity for the organization (Sousa \& Rocha, 2019). All these benefits, described at three different levels, are sketched in the structure of Figure 3, below.

Digital leaders must acknowledge these positive effects of knowledge re-use and connect the dots in order to elaborate knowledge management strategies for their organizations. According to literature discussions (Sheninger, 2019), we can propose a series of possible leadership strategies in the domain of knowledge management in the digital business environment. 


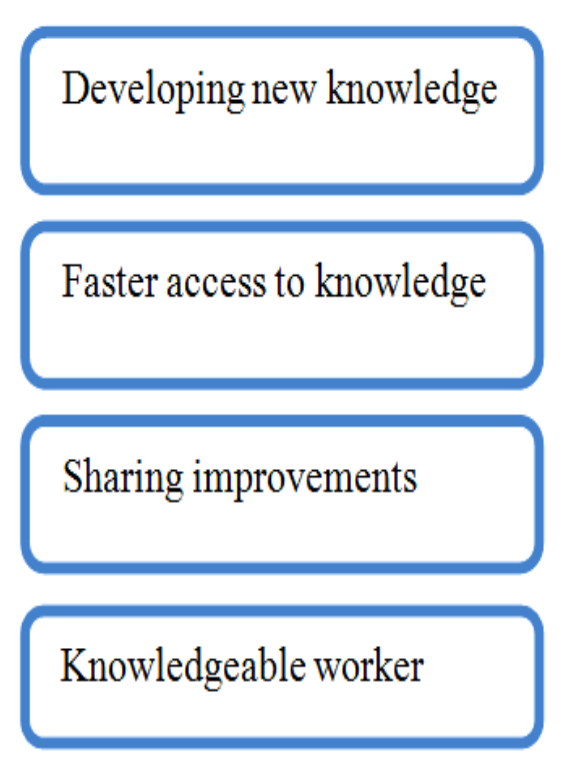

WORKERS LEVEL

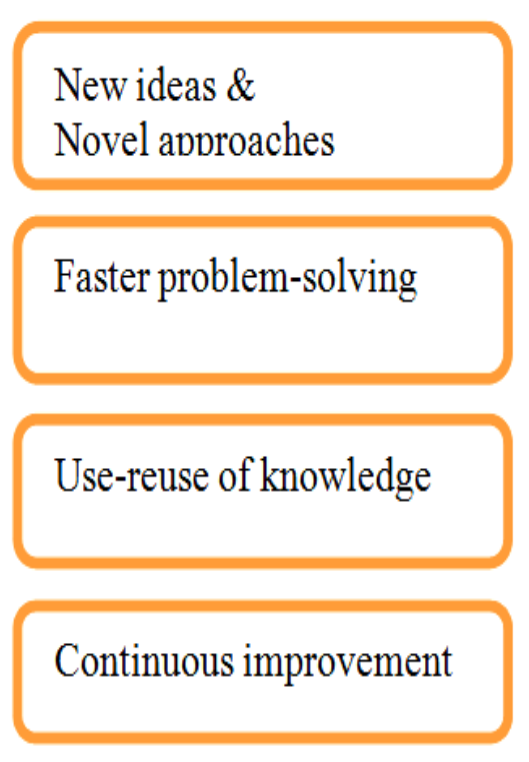

PROCESSES LEVEL

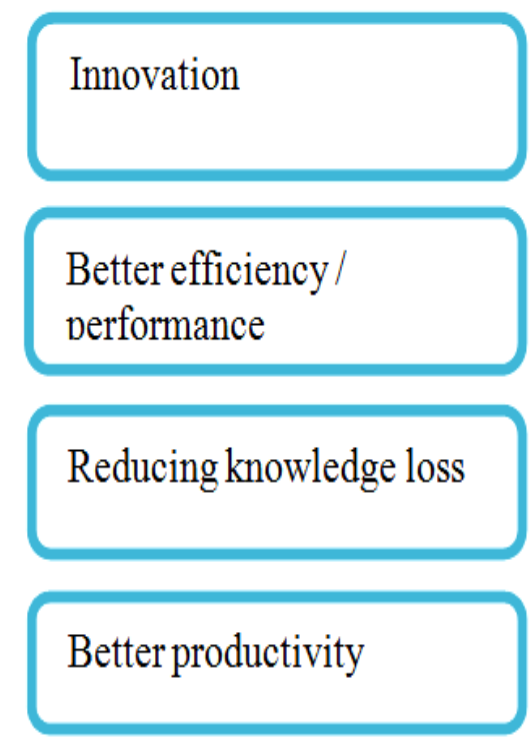

ORGANIZATION LEVEL

PICBE | 653

Figure 3. Positive effects of knowledge re-use at three different levels

Source: adapted after (Sousa \& Rocha, 2019)

\section{Concluding remarks}

In conclusion, the digital environment has a powerful effect throughout its extremely fast reply with feedback from the market, from the customers, from the mass-media, and so on. This boomerang effect must be anticipated when starting the implementation of a new digital strategy in order to be sound and to communicate the correct message for the online policy of the organization.

When preparing their strategy, leaders must elaborate a detailed content plan in order to enable them to discover what exactly is that they want to empower throughout their online strategy. Generally speaking, working in the digital environment means working actually connected with everyone, the whole world wide web. If we consider singular digital channels, like Social Media, it is also an ever-growing community which implies a continuous monitoring of the compatibility with the adopted strategy.

A distinct feature of the digital leader is the esthetics. The online audience is highly demanding and digital leaders must understand how to apply branding, visuals and videos, as a significant part of their online strategies. Furthermore, there must be a lean alignment of all digital pieces, like the website, the content, the strategy and the customers funnel. Overall, digital leaders realize that the combination of advertising and analytics is critical for the long-run success of their business, expanding their audience and generating business growth.

Leadership in the digital age, develops within a digital framework, according to digital coordinates and throughout digital resources, which change dramatically its appearance but the 
core of leadership remains the same. We reinforce the idea that a leader's essential characteristics are timeless regardless of the substantial or superficial changes generated by digitalization.

\section{References}

Ahmad, N., Lodhi, M. S., Zaman, K., \& Naseem, I. (2017). Knowledge management: a gateway for organizational performance. Journal of the Knowledge Economy, Vol. 8(No. 3), 859876.

Allcott, H., \& Gentzkow, M. (2017). Social media and fake news in the 2016 election. Journal of Economic Perspectives, 31(2), 211-36.

Avolio, B.J., \& Gardner, W.L., (2005). Authentic leadership development: Getting to the root of positive forms of leadership. The Leadership Quarterly. 16, 315-338.

Avital, M., Mathiassen, L., \& Schultze, U. (2017). Alternative genres in information systems research. European Journal of Information Systems, 26(3), 240-247.

Băeșu, C. (2018). Leadership based on emotional intelligence in modern organizations, The USV Annals of Economics and Public Administration, vol. 18, ISSUE 2(28).

Bejinaru, R. (2019). Impact of digitalization on education in the knowledge economy, Management Dynamics in Knowledge Economy, 7(3), 367-380.

Bejinaru, R. (2017). Knowledge strategies aiming to improve the intellectual capital of universities, Management \& Marketing. Challenges for the Knowledge Society, Vol. 12, No. 3, pp. 500-523.

Bejinaru, R., \& Prelipcean, G. (2017). Successful strategies to be learnt from world-class universities, The 11th International Conference on Business Excellence Strategy, Complexity and Energy in changing times, 30-31 March 2017, Bucharest, University of Economic Studies, pp. 469-492, DeGruyter Open, Vol 11(1) July 2017, pp. 350-358.

Bejinaru, R., \& Hapenciuc, C.V. (2016). Valorization of the learning organization's principles in the business HES, Strategica -International Conference - Fourth Edition, "Local versus Global - Opportunities and Risks in the Contemporary Business Environment", October 20th-21st, Bucharest: Tritonic, pp. 600-611.

Bejinaru, R., \& Iordache, S. (2010). Knowledge channeling in the learning organization, 5th International Conference on Business Excellence, 15-16 October 2010 Braşov, Infomarket Publishing House, Romania, pg. 59.

Bloomberg, J. (2018). Digitization, digitalization, and digital transformation: confuse them at your peril. Forbes, retrieved 28 August 2019, https://www.forbes.com/sites/jasonbloomberg/2018/04/29/ digitization-digitalization-anddigital-transformation-confuse-them-at-your-peril/\#78e677fd2f2c.

Bratianu, C. (2018a). Intellectual capital research and practice: 7 myths and one golden rule. Management \& Marketing. Challenges for the Knowledge Society, 13(2), 859-879.

Bratianu, C. (2018b). A holistic approach to knowledge risk. Management Dynamics in the Knowledge Economy, 6(4), 593-607.

Bratianu, C., \& Bejinaru, R. (2019). The theory of knowledge fields: a thermodynamics approach. Systems, 7, 20.

Bratianu, C., \& Bejinaru, R. (2020). Knowledge dynamics: a thermodynamics approach, Kybernetes, 49(1), 6-21.

Bratianu, C., Hadad, S., \& Bejinaru R. (2020). Paradigm shift in business education: a competence-based approach. Sustainability, 12(4), 1348-1365. 
Bratianu, C., \& Pinzaru, F. (2015). University governance as a strategic driving force. In Dias Ronco, J.C. (Ed.). Proceedings of the $11^{\text {th }}$ European Conference on Management, Leadership and Governance, Military Academy, Lisbon, Portugal, 12-13 November 2015, pp. 28-35. Reading: Academic Conferences and Publishing International.

Costa, V., \& Monteiro, S. (2016). Key knowledge management processes for innovation: a systematic literature review. VINE Journal of Information and Knowledge Management Systems, Vol. 46(No. 3), 386-410.

CEC Report, (2018). Management in the Digital Era, CEC European Managers, Rue de la loi 81a, 1040 Brussels Belgium.

Chew, E.K. (2013). Value Co-creation in the Organizations of the Future. Puslished in: Collin, J., Hiekkanen, K., Korhonen, J.J., Halén, M., Itälä, T., Helenius, M., others, 2015. IT Leadership in Transition-The Impact of Digitalization on Finnish Organizations.

Copeland, M.K., (2014). The emerging significance of values based leadership: a literature review. International Journal of Leadership Studies. Vol 8, 105-135.

Culpin, V., Millar, C., Peters, K., Lyons, S.T., Schweitzer, L., \& Ng, E.S. (2015). How have careers changed? An investigation of changing career patterns across four generations. Journal of Managerial Psychology,30(1), 8-21.

Dima, A.M., \& Ghinea, V. (2016). A model of academic leadership. In Pinzaru, F. \& Bratianu, C. (Eds.). Proceedings of the $12^{\text {th }}$ European Conference on Management, Leadership and Governance, pp. 61-70, Faculty of Management, National University of Political Studies and Public Administration, Bucharest, Romania, 10-11 November 2016. Reading: Academic Conferences and Publishing International.

Dima, A.M., Hadad, S., \& Luchian, I. (2017). Review on the dimensions of business-university alliances, Proceedings of the International Conference on Business Excellence, 11 (1), 6473.

Do, N.T.H., Van Nguyen, P., \& Dinh, P.U. (2018). A Qualitative Study Regarding the Leadership Traits and Styles of the Millennial Generation in the Manufacturing Industry. International Journal of Engineering \& Technology, 7(3), 52-58.

Elvington, S. (2017). Evolving Leadership for the Digital Age, Insights on learning, leadership, and professional development- blog, accessed 4 February 2020 at: https://blogs.oracle.com/sandye/evolving-leadership-for-the-digital-age.

Griffith, D.A., \& Hoppner, J. (2013). Global marketing managers: improving global strategy through soft skill development. International Marketing Review, 30(1), 21-51.

Hadad, S. (2017). Strategies for developing knowledge economy in Romania, Management \& Marketing. Challenges for the Knowledge Society, 12 (3), 416-430.

Hadad, S. \& Bratianu, C. (2019). Dematerialization of banking products and services in the digital era, Management \& Marketing. Challenges for the Knowledge Society, Vol. 14, No. 3, pp. 318-337.

Hapenciuc, C.V., Bejinaru, R., Roman, C., \& Neamtu, D.M. (2016). The role of HES within the evolution of the business sector, EDULEARN-8th annual International Conference on Education and New Learning Technologies Barcelona (Spain), 4th - 6th of July, pp.53095314.

Hill, L.A., (2013). Becoming a Manager: How New Managers Master the Challenges of Leadership. Harvard Business Press. 
Mahdi, O. R., Nassar, I. A., \& Almsafir, M. K. (2018). Knowledge management processes and sustainable competitive advantage: An empirical examination in private universities. Journal of Business Research.

Maravilhas, S., \& Martins, J. (2018). Strategic knowledge management a digital environment: Tacit and explicit knowledge in Fab Labs. Journal of Business Research.

Neamtu, D., Hapenciuc, V., \& Bejinaru, R. (2019). The impact of digitalization on business

PICBE | 656 sector development in the knowledge economy, Proceedings of the International Conference on Business Excellence 2019, Bucharest, Romania, 13(1), pp. 479-491.

Parviainen, P., Tihinen, M., Kääriäinen, J. \& Teppola, S. (2017). Tackling the digitalization challenge: how to benefit from digitalization in practice, International Journal of Information Systems and Project Management, 5(1), 63-77.

Ready, D., Cohen, C., Kiron, D. \& Pring, B. (2020) The new leadership playbook for the digital age, MIT Sloan Management Review, January 2020.

Sheninger, E. (2019). Digital leadership: changing paradigms for changing times, Corwin SAGE Publications, London.

Sousa, M.J. \& Rocha, A. (2019). Strategic knowledge management in the digital era, Journal of Business Research, Special Issue, 49, 223-226.

Vătămănescu, E.-M., Andrei, A.G., Nicolescu, L., Pînzaru, F., \& Zbuchea, A. (2017). The influence of competitiveness on smes internationalization effectiveness. Online versus offline business networking. Information Systems Management, 34(3), 205-219.

Weinman, J. (2015). Digital discipline - attaining market leadership via the cloud, big data, social, mobile \& internet of the things, John Wiley \& Sons, Ltd.

Yukl, G.A., (2012). Leadership in Organizations, 8th edition. Pearson Education.

Zhu, P. (2015). Digital master: debunk the myths of enterprise digital maturity, Lulu Publishing services. 